\title{
Child safety: a neglected priority
}

\author{
AB (Sebastian) van As, Dan J Stein \\ Cape Town, South Africa
}

$\mathrm{D}$ uring the first week of 2009 a number of children were treated in the Trauma Unit at the Red Cross War Memorial Children's Hospital in Cape Town. A 2-year-old girl visiting from the province fell in front of a bus while her mother was being robbed of a cell phone in one of the suburbs. The bus could not avoid the little girl, crushed her and killed her. A 6-yearold girl travelling back from the city to her home with her family was severely injured when someone threw a brick at the front windscreen of the car, breaking it and instantly killing the driver, after which the car left the road and all the passengers were seriously injured. Three children were electrocuted when their homes, which were disconnected by the municipality because of nonpayment, and were illegally rewired, leaving live wires exposed and killing the children. Another 6-year-old girl was hit by a stray bullet in a gang fight. Although all these deaths are quite different in nature, a similar pattern is recognizable. Adults, in active chase for their own gratification are injuring children lethally in the process. It is unlikely that in any of these cases the children were directly targeted, however, they died while adults were pursuing their own criminal interests. A study performed a few years ago at the Red Cross Children's Hospital indicated that of all children presenting with head injuries after abuse, almost $50 \%$ of them were injured when adults were fighting with each other. ${ }^{[1]}$ While these examples may not be mainstream, they highlight a rather unknown mechanism of childhood injury and expose how little we really do know about childhood injuries and how to prevent them.

\footnotetext{
Author Affiliations: Trauma Unit, University of Cape Town, Red Cross War Memorial Children's Hospital, Rondebosch, 7701 Cape Town, South Africa (van As AB, Stein DJ)

Corresponding Author: Prof. AB (Sebastian) van As, MBChB MMed MBA FCS PhD, Head Trauma Unit, University of Cape Town, Red Cross War Memorial Children's Hospital, Rondebosch, 7701 Cape Town, South Africa (Tel: 00-27-21-6585012; Fax: 00-27-21-6856632; Email: Sebastian. vanas@uct.ac.za)

\section{The World Report on Child Injury Prevention} In December 2008 the World Health Organization (WHO) and UNICEF published the World Report on Child Injury Prevention. ${ }^{[2]}$ Approximately 200 participants from over 50 countries worked on this report for a period of two years. Childhood injuries and death form a major public health problem requiring urgent attention. Injury and violence are the major killers of children throughout the world, responsible for approximately 1 million deaths of children under the age of 18 years (WHO Global Burden of Disease 2004) with accidental injuries accounting for almost $90 \%$ of these cases, and the remainder are due to violence or maltreatment. The exact ratio of accidental to violence/ maltreatment cases is unknown, but studies of infant deaths suggest the latter are underreported. ${ }^{[3]}$ In addition to these 1 million deaths, tens of millions of children require prolonged hospital care for their injuries, and many of the children are left with a degree of disability, often lifelong. This burden of injuries is severely biased towards low and middle income countries; it is estimated that over $95 \%$ of all deaths in children are due to injury in these countries. Child safety is a rather wide concept and it is important to differentiate between the various categories.

\section{Accidental injuries}

The top three causes of child mortality from accidental injury are road traffic accidents (32\%), drowning (17\%) and burns $(9 \%) \cdot{ }^{[2]}$ All of these are highly preventable. Factors which influence injuries are supervision of particularly small children, a single caregiver, a home with multiple siblings, substance abuse in the caregiver, and large families ${ }^{[2]}$ Although these risk factors are located within particular households, the larger context in which they operate cannot be ignored; child safety is ultimately a matter of crucial concern for all societies. A number of studies have demonstrated the feasibilities of interventions to reduce child mortality and morbidity from accidental injury. ${ }^{[4]}$ The most vulnerable among children are those under the age of 6 years. These little children have not yet developed the capacity to assess dangers in their environment and to avoid them and are therefore completely dependent on the protection 
of older caregivers. The high incidence of child injury death is a direct result of the low levels of supervision of small children and suboptimal health care. Although children may be mentioned in many discussions around the world, their interests do not form an integral part of societal infrastructural design and activities.

\section{Non-accidental injuries (physical and sexual violence)}

The WHO defines violence as the intentional use of physical force or power, threatened or actual, against oneself, another person, or against a group or community that either results in or has a high likelihood of injury, death, psychological harm, mal-development or deprivation. This definition emphasizes intentionality irrespective of the outcome it produces. ${ }^{[3]}$

The WHO definitions of child abuse or maltreatment are broader, including all forms of physical and/or emotional ill-treatment, sexual abuse, neglect or negligent treatment or commercial or other exploitation, resulting in actual or potential harm to the child's health, survival, development or dignity in the context of the relationship of responsibility, trust and power. ${ }^{[3]}$ At our hospital, where we treat approximately 10000 injured children under the age of 13 years annually, $5 \%$ of all trauma patients are the victims of abuse. The main types are physical abuse and sexual abuse. The global estimates of child homicide suggest that infants and very young children are at the greatest risk in the $0-4$ year age group, more than double of that in the 5-14 year old group. ${ }^{[2]}$

\section{Psychological trauma}

The most important protective resource to enable a child to cope with exposure to violence is a strong relationship with a competent, caring, and positive adult, most often a parent. It is often absent in low and middle income countries where caregivers struggle to be permanently available while the child is growing up. ${ }^{[5]}$ The problem is aggravated by the relatively young age of parents in many regions. Parents may be unable to protect their children and keep them safe; parents themselves may have been exposed to trauma, and suffer from symptoms of depression or post traumatic stress disorder and so emotionally unavailable for their children. Parents who are living with chronic community violence frequently describe their sense of helplessness and frustration with an inability to protect their children and keep them safe, even in their own neighborhoods. Nevertheless, even in such circumstances, it is possible to intervene helpfully. ${ }^{[6]}$

\section{Media violence}

Increasingly over the past two decades, violence is regarded as a "public health epidemic". ${ }^{[2]}$ Children are exposed to violence in their communities, in their families as well as in the media. Besides the real violence which children endure, the media play an aggravating role. A typical American child watches 20 hours of television a week and by the age of 18 years would have seen 16000 simulated murders and 200000 acts of violence. ${ }^{[5]}$ The perpetrators of this portrayed violence are usually pictured in a positive manner, with hardly any attention to the victim and the injuries inflicted. The consequences of the inflicted violence are very rarely portrayed in an appropriate manner. It has been suggested that infants and toddlers who witness violence in their homes or community show excessive irritability, immature behaviour, sleep disturbances, emotional distress, fears of being alone and regression in toileting and language. ${ }^{[6]}$ Nearly one decade ago (In July 2000), a joint statement of the Public Health Community in the USA consisting of many groups, including pediatricians, psychiatrists and psychologists, issued a joint statement concluding that over 1000 studies indicated there was a causal association between media (TV, films, video games) violence and aggressive behaviour in some children. ${ }^{[7]}$

\section{Risk factors for child injuries}

Most injuries in small children occur in and around the home, while bigger, school-going children are the most vulnerable on public roads. It is interesting and important to note that both accidental and nonaccidental (violence) injuries share numerous risk as well as protective factors. ${ }^{[8]}$ Traditionally, violence prevention strategies have focused on people and behaviour, while accidental strategies have far more been focused on objects and environment. It will be good for child safety when the two sectors cooperate in the future and share their experiences and programs. Risk factors for child abuse are young age, gender, caregiver and family characteristics, family structure and resources, family size and household composition, personality and behavioral characteristics and a prior history of abuse and violence in the home. Community risk factors include increasing poverty and decreasing social capital. ${ }^{[2]}$

Alcohol and other substance abuse within our society are important risk factors for many types of trauma, accidental and non-accidental. There are numerous well-proven strategies to prevent and diminish the negative effects of substances abuse among children; early intervention is a key component 
of successful programs. ${ }^{[9]}$

\section{Conclusion}

There is a growing evidence based on the extent to which child injury is a major public health problem, and on the specific risk factors for such injury. Despite the need for urgent attention, child injuries have long been neglected and are largely absent from present child survival initiatives. Numerous programs related to child survival have targeted infectious diseases, malnutrition and dehydration. To achieve maximal effects, these programs need to be supplemented by initiatives that specifically focused on the prevention of accidental as well as interpersonal violence. ${ }^{[4]}$

Often risk factors are easily addressed: simple improvements to playgrounds may enhance safety, obvious social adjustments may provide parents with more parenting time. Child injury is less commonly the result of intentional abuse and maltreatment than the consequence of a failure to be aware of child injury and to appreciate the need for appropriate interventions. Indeed, a range of potential interventions have been shown effective and cost-efficient in reducing child injury. However, such interventions may require the involvement of many sectors, and there is often a lack of political will to make complex social changes that are needed for reducing injury. There is a need for more research on how optimally to encourage and implement such reforms. Perhaps promoting awareness among adults about the unfortunate plight of so many children may be a more effective strategy to reduce child injuries than strategies aimed at preventing intentional child abuse. Certainly child safety should be higher on the agenda, at home, in the community, at national and international levels.
Funding: None.

Ethical approval: Not needed.

Competing interest: None.

Contributors: van As AB was responsible for the concept, design and drafting of the manuscript. Stein DJ critically revised the manuscript. Both authors approved the final version for publication.

\section{References}

1 Fieggen AG, Wiemann M, Brown C, van As AB, Swingler GH, Peter JC. Inhuman shields-children caught in the crossfire of domestic violence. S Afr Med J 2004;94:293-296.

2 Peden M, Oyegbite K, Ozanne-Smith J. World Report on Child Injury Prevention. Geneva: WHO and UNICEF, 2008. http:// www.who.int/violence_injury_prevention/child/en/ (accessed August 19, 2010)

3 Peden M, Hyder AA. Time to keep African kids safer. S Afr Med J 2009;99:36-37.

4 Krug EG, Dahlberg LL, Mercy JA, Zwi A, Lozano R. World Report on Violence and Health, 2002. Geneva, World Health Organization. http://www.who.int/violence_injury_prevention/ violence/world_report/en/ (accessed August 19, 2010)

5 American Psychiatric Association. Psychiatric effects of media violence. APA fact sheet series. APA Online Public Information. American Psychiatric Association. http://www.aap.org/advocacy/ releases/jstmtevc.htm (accessed August 19, 2010)

6 Osofsky JD. The impact of violence on children. Future Child 1999;9:33-49.

7 http://www.nordicom.gu.se/cl/publ/archive/NL_2_2000.pdf (accessed February 23, 2009).

8 Peterson L, Brown D. Integrating child injury and abuse/neglect research: common histories, etiologies, and solutions. Psychol Bull 1994;116:293-315.

9 Cunradi CB, Caetano R, Schafer J. Alcohol-related problems, drug use, and male intimate partner violence severity among US couples. Alcohol Clin Exp Res 2002;26:493-500.

Received March 30, 2009

Accepted after revision December 30, 2009 